\title{
Some coupled coincidence and common fixed point results for a hybrid pair of mappings in 0-complete partial metric spaces
}

\author{
Wei Long ${ }^{1 *}$, Satish Shukla², Stojan Radenović ${ }^{3}$ and Slobodan Radojević ${ }^{3}$
}

"Correspondence:
hopelw@126.com
'College of Mathematics and
Information Science, Jiangxi Normal
University, Nanchang, Jiangxi
330022, People's Republic of China
Full list of author information is
available at the end of the article

available at the end of the article

\begin{abstract}
In this paper we extend some coupled coincidence and common fixed point theorems for a hybrid pair of mappings obtained by Abbas et al. (Fixed Point Theory Appl. 2012:4, 2012, doi:10.1186/1687-1812-2012-4) from the complete metric space to 0 -complete partial metric spaces. An example showing that this extension is proper is given.

MSC: $47 \mathrm{H} 10 ; 54 \mathrm{H} 25$

Keywords: set-valued mapping; hybrid pair of mappings; coupled fixed point; coupled coincidence point; partial metric space
\end{abstract}

\section{Introduction}

Let $A$ be any nonempty subset of a metric space $(X, d)$. For $x \in X$, define

$$
d(x, A)=\inf \{d(x, y): y \in A\} .
$$

Let $C B(X)$ denote the set of all nonempty closed bounded subset of $X$. For $A, B \in C B(X)$, define

$$
\begin{aligned}
& \delta(A, B)=\sup \{d(x, B): x \in A\}, \\
& H(A, B)=\max \{\delta(A, B), \delta(B, A)\} .
\end{aligned}
$$

Then $H$ is a metric on $C B(X)$ and is called a Hausdorff metric.

Nadler [1] generalized the Banach contraction mapping principle to set-valued functions and proved the following fixed point theorem.

Theorem 1 Let $(X, d)$ be a complete metric space and let $T$ be a mapping from $X$ into $C B(X)$ such that for all $x, y \in X$,

$$
H(T x, T y) \leq \lambda d(x, y)
$$

where $0 \leq \lambda<1$. Then $T$ has a fixed point.

\section{Springer}

O 2013 Long et al: licensee Springer. This is an Open Access article distributed under the terms of the Creative Commons Attribution License (http://creativecommons.org/licenses/by/2.0), which permits unrestricted use, distribution, and reproduction in any medium, provided the original work is properly cited. 
Later, an interesting and rich fixed point theory was developed. On the other hand, Matthews [2] introduced the notion of a partial metric space as a part of the study of denotational semantics of dataflow networks, with the interesting property 'non-zero selfdistance' in space. He showed that the Banach contraction mapping theorem can be generalized to the partial metric context for applications in program verification. Subsequently, several authors (see, e.g., [3-22]) derived fixed point theorems in partial metric spaces. Romaguera [17] introduced the notion of 0 -Cauchy sequence, 0 -complete partial metric spaces and proved some characterizations of partial metric spaces in terms of completeness and 0-completeness. Recently, Aydi et al. [9] introduced the notion of a partial Hausdorff metric and extended the Nadler's theorem in partial metric spaces.

Bhaskar and Lakshmikantham [23] introduced the concept of a coupled fixed point and established some coupled fixed point theorems in partially ordered sets. As an application, they studied the existence and uniqueness of a solution for a periodic boundary value problem associated with a first-order ordinary differential equation. Recently Abbas et al. [24] extended these concepts to set-valued mappings and obtained coupled coincidence points and coupled common fixed point theorems involving a hybrid pair of single-valued and multi-valued maps satisfying generalized contractive conditions in the framework of a complete metric space (see also [25, 26]). The study of a coincidence point and common fixed points of a hybrid pair of mappings in Banach spaces and metric spaces is interesting and well developed. For applications of hybrid fixed point theory, we refer to [27-30].

In this paper, we extend and generalize the results of Abbas et al. [24] and Aydi et al. [9] for a hybrid pair of mappings in 0 -complete partial metric spaces. Also, some new results are obtained. An example is included to support our results.

\section{Preliminaries}

Consistent with $[2,8,9,16,17,19]$, the following definitions and results will be needed in the sequel.

Definition 1 A partial metric on a nonempty set $X$ is a function $p: X \times X \rightarrow \mathbb{R}^{+}\left(\mathbb{R}^{+}\right.$ stands for nonnegative reals) such that for all $x, y, z \in X$,

(P1) $x=y \Leftrightarrow p(x, x)=p(x, y)=p(y, y)$,

(P2) $p(x, x) \leq p(x, y)$,

(P3) $p(x, y)=p(y, x)$,

(P4) $p(x, y) \leq p(x, z)+p(z, y)-p(z, z)$.

A partial metric space is a pair $(X, p)$ such that $X$ is a nonempty set and $p$ is a partial metric on $X$.

It is clear that if $p(x, y)=0$, then from (P1) and (P2) $x=y$. But if $x=y, p(x, y)$ may not be 0 . Also, every metric space is a partial metric space, with zero self-distance.

Example 1 If $p: \mathbb{R}^{+} \times \mathbb{R}^{+} \rightarrow \mathbb{R}^{+}$is defined by $p(x, y)=\max \{x, y\}$, for all $x, y \in \mathbb{R}^{+}$, then $\left(\mathbb{R}^{+}, p\right)$ is a partial metric space.

Some more examples of a partial metric space can be seen in $[2,9,16]$.

Each partial metric on $X$ generates a $T_{0}$ topology $\tau_{p}$ on $X$ which has as a base the family of open $p$-balls $\left\{B_{p}(x, \epsilon): x \in X, \epsilon>0\right\}$, where $B_{p}(x, \epsilon)=\{y \in X: p(x, y)<p(x, x)+\epsilon\}$ for all $x \in X$ and $\epsilon>0$. 
Theorem 2 [2] For each partial metric $p: X \times X \rightarrow \mathbb{R}^{+}$, the pair $(X, d)$, where $d(x, y)=$ $2 p(x, y)-p(x, x)-p(y, y)$ for all $x, y \in X$, is a metric space.

Here $(X, d)$ is called an induced metric space and $d$ is an induced metric. In further discussion, unless specified otherwise, $(X, d)$ will represent an induced metric space.

Let $(X, p)$ be a partial metric space.

(1) A sequence $\left\{x_{n}\right\}$ in $(X, p)$ converges to a point $x \in X$ if and only if $p(x, x)=\lim _{n \rightarrow \infty} p\left(x_{n}, x\right)$.

(2) A sequence $\left\{x_{n}\right\}$ in $(X, p)$ is called a Cauchy sequence if there exists (and is finite) $\lim _{n, m \rightarrow \infty} p\left(x_{n}, x_{m}\right)$.

(3) $(X, p)$ is said to be complete if every Cauchy sequence $\left\{x_{n}\right\}$ in $X$ converges with respect to $\tau_{p}$ to a point $x \in X$ such that $p(x, x)=\lim _{n, m \rightarrow \infty} p\left(x_{n}, x_{m}\right)$.

(4) A sequence $\left\{x_{n}\right\}$ in $(X, p)$ is called 0 -Cauchy sequence if $\lim _{n, m \rightarrow \infty} p\left(x_{n}, x_{m}\right)=0$. The space $(X, p)$ is said to be 0 -complete if every 0 -Cauchy sequence in $X$ converges with respect to $\tau_{p}$ to a point $x \in X$ such that $p(x, x)=0$.

Lemma $1[2,17,19]$ Let $(X, p)$ be a partial metric space and $\left\{x_{n}\right\}$ be any sequence in $X$.

(i) $\left\{x_{n}\right\}$ is a Cauchy sequence in $(X, p)$ if and only if it is a Cauchy sequence in the metric space $(X, d)$.

(ii) $(X, p)$ is complete if and only if the metric space $(X, d)$ is complete. Furthermore, $\lim _{n \rightarrow \infty} d\left(x_{n}, x\right)=0$ if and only if $p(x, x)=\lim _{n \rightarrow \infty} p\left(x_{n}, x\right)=\lim _{n, m \rightarrow \infty} p\left(x_{n}, x_{m}\right)$.

(iii) Every 0 -Cauchy sequence in $(X, p)$ is Cauchy in $(X, d)$.

(iv) If $(X, p)$ is complete, then it is 0-complete.

The converse assertions of (iii) and (iv) do not hold. Indeed, the partial metric space $(\mathbb{Q} \cap$ $[0, \infty), p)$, where $\mathbb{Q}$ denotes the set of rational numbers and the partial metric $p$ is given by $p(x, y)=\max \{x, y\}$ for all $x, y \in X$, provides an easy example of a 0 -complete partial metric space which is not complete. It is easy to see that every closed subset of a 0 -complete partial metric space is 0 -complete.

Let $(X, p)$ be a partial metric space. Let $C B^{p}(X)$ be the family of all nonempty, closed and bounded subsets of the partial metric space $(X, p)$ induced by the partial metric $p$. Note that closedness is taken from $\left(X, \tau_{p}\right)\left(\tau_{p}\right.$ is the topology induced by $\left.p\right)$ and boundedness is given as follows: $\mathrm{A}$ is a bounded subset in $(X, p)$ if there exist $x_{0} \in X$ and $M \geq 0$ such that for all $a \in A$, we have $a \in B_{p}\left(x_{0}, M\right)$, that is, $p\left(x_{0}, a\right)<p(a, a)+M$.

For $A, B \in C B^{p}(X)$ and $x \in X$, define

$$
p(x, A)=\inf \{p(x, a): a \in A\}, \quad \delta_{p}(A, B)=\sup \{p(a, B): a \in A\} .
$$

Lemma 2 [8] Let $(X, p)$ be a partial metric space, $A \subset X$. Then $a \in \bar{A}$ if and only if $p(a, A)=$ $p(a, a)$.

Proposition 1 [9] Let $(X, p)$ be a partial metric space. For any $A, B, C \in C B^{p}(X)$, we have the following:

(i) $\delta_{p}(A, A)=\sup \{p(a, a): a \in A\}$;

(ii) $\delta_{p}(A, A) \leq \delta_{p}(A, B)$;

(iii) $\delta_{p}(A, A)=0$ implies that $A \subseteq B$;

(iv) $\delta_{p}(A, B) \leq \delta_{p}(A, C)+\delta_{p}(C, B)-\inf _{c \in C} p(c, c)$. 
Let $(X, p)$ be a partial metric space. For $A, B \in C B^{p}(X)$, define

$$
H_{p}(A, B)=\max \left\{\delta_{p}(A, B), \delta_{p}(B, A)\right\} .
$$

Proposition 2 [9] Let $(X, p)$ be a partial metric space. For $A, B, C \in C B^{p}(X)$, we have

(h1) $H_{p}(A, A) \leq H_{p}(A, B)$;

(h2) $H_{p}(A, B)=H_{p}(B, A)$;

(h3) $H_{p}(A, B) \leq H_{p}(A, C)+H_{p}(C, B)-\inf _{c \in C} p(c, c)$.

Corollary 1 [9] Let $(X, p)$ be a partial metric space. For $A, B \in C B^{p}(X)$, the following holds:

$$
H_{p}(A, B)=0 \quad \text { implies that } A=B .
$$

In view of Proposition 2 and Corollary 1, we call the mapping $H_{p}: C B^{p}(X) \times C B^{p}(X) \rightarrow$ $[0, \infty)$ a partial Hausdorff metric induced by $p$.

Lemma 3 [9] Let $(X, p)$ be a partial metric space, $A, B \in C B^{p}(X)$ and $h>1$. For any $a \in A$, there exists $b=b(a) \in B$ such that $p(a, b) \leq h H_{p}(A, B)$.

The following lemma is crucial for the proof of our main result and its proof is similar to Lemma 3.

Lemma 4 Let $(X, p)$ be a partial metric space and $A, B \in C B^{p}(X), a \in A$. Let $\epsilon>0$ be arbitrary, then there exists $b=b(a) \in B$ such that

$$
p(a, b) \leq H_{p}(A, B)+\epsilon .
$$

Definition 2 [24] Let $X$ be a nonempty set, $F: X \times X \rightarrow 2^{X}$ (collection of all nonempty subsets of $X)$ and $g: X \rightarrow X$. An element $(x, y) \in X \times X$ is called

(i) a coupled fixed point of $F$ if $x \in F(x, y)$ and $y \in F(y, x)$;

(ii) a coupled coincidence point of the hybrid pair $\{F, g\}$ if $g x \in F(x, y)$ and $g y \in F(y, x)$;

(iii) a coupled point of coincidence if there exists $(u, v) \in X \times X$ such that $x=g u \in F(u, v)$ and $y=g v \in F(v, u) ;$

(iv) a coupled common fixed point of the hybrid pair $\{F, g\}$ if $x=g x \in F(x, y)$ and $y=g y \in F(y, x)$.

Definition 3 Let $X$ be a nonempty set, let $F: X \times X \rightarrow 2^{X}$ and $g: X \rightarrow X$ be two mappings. The hybrid pair $\{F, g\}$ is called weakly compatible if $g F(x, y) \subseteq F(g x, g y)$ and $g F(y, x) \subseteq F(g y, g x)$ whenever $(x, y)$ is a coupled coincidence point of the hybrid pair $\{F, g\}$.

Now we can state our main results.

\section{Main results}

The following result extends and generalizes the main result of [24] in partial metric spaces. 
Theorem 3 Let $(X, p)$ be a 0 -complete partial metric space, let $F: X \times X \rightarrow C B^{p}(X)$ and $g: X \rightarrow X$ be mappings satisfying

$$
\begin{aligned}
H_{p}(F(x, y), F(u, v)) \leq & a_{1} p(g x, g u)+a_{2} p(g y, g v)+a_{3} p(F(x, y), g x) \\
& +a_{4} p(F(x, y), g u)+a_{5} p(F(u, v), g x) \\
& +a_{6} p(F(u, v), g u)
\end{aligned}
$$

for all $x, y, u, v \in X$, where $a_{i}$ are nonnegative reals such that $\sum_{i=1}^{6} a_{i}<1$. If $F(X \times X) \subseteq g(X)$ and $g(X)$ is a closed subset of $X$, then $F$ and $g$ have a coupled point of coincidence $\left(w_{c}, z_{c}\right) \in$ $X \times X$ and $p\left(w_{c}, w_{c}\right)=p\left(z_{c}, z_{c}\right)=0$.

Proof Let $x_{0}, y_{0} \in X$ be arbitrary, then $F\left(x_{0}, y_{0}\right), F\left(y_{0}, x_{0}\right) \in C B^{p}(X)$. As $F(X \times X) \subseteq$ $g(X)$, we can choose $g x_{1} \in F\left(x_{0}, y_{0}\right)$ and $g y_{1} \in F\left(y_{0}, x_{0}\right)$ for some $x_{1}, y_{1} \in X$. Again, as $F\left(x_{1}, y_{1}\right), F\left(y_{1}, x_{1}\right) \in C B^{p}(X)$ and $F(X \times X) \subseteq g(X)$, so by Lemma 4 , for any $\epsilon>0$, there exist $g x_{2} \in F\left(x_{1}, y_{1}\right)$ and $g y_{2} \in F\left(y_{1}, x_{1}\right)$ such that

$$
\begin{aligned}
& p\left(g x_{1}, g x_{2}\right) \leq H_{p}\left(F\left(x_{0}, y_{0}\right), F\left(x_{1}, y_{1}\right)\right)+\epsilon, \\
& p\left(g y_{1}, g y_{2}\right) \leq H_{p}\left(F\left(y_{0}, x_{0}\right), F\left(y_{1}, x_{1}\right)\right)+\epsilon .
\end{aligned}
$$

Continuing this process, we obtain two sequences $\left\{x_{n}\right\}$ and $\left\{y_{n}\right\}$ in $X$ such that

$$
\begin{aligned}
& g x_{n+1} \in F\left(x_{n}, y_{n}\right) \quad \text { and } \quad g y_{n} \in F\left(y_{n}, x_{n}\right), \\
& p\left(g x_{n}, g x_{n+1}\right) \leq H_{p}\left(F\left(x_{n-1}, y_{n-1}\right), F\left(x_{n}, y_{n}\right)\right)+\epsilon^{n}, \\
& p\left(g y_{n}, g y_{n+1}\right) \leq H_{p}\left(F\left(y_{n-1}, x_{n-1}\right), F\left(y_{n}, x_{n}\right)\right)+\epsilon^{n} .
\end{aligned}
$$

From the above inequalities and (1), we obtain

$$
\begin{aligned}
p\left(g x_{n}, g x_{n+1}\right) \leq & H_{p}\left(F\left(x_{n-1}, y_{n-1}\right), F\left(x_{n}, y_{n}\right)\right)+\epsilon^{n} \\
\leq & a_{1} p\left(g x_{n-1}, g x_{n}\right)+a_{2} p\left(g y_{n-1}, g y_{n}\right) \\
& +a_{3} p\left(F\left(x_{n-1}, y_{n-1}\right), g x_{n-1}\right)+a_{4} p\left(F\left(x_{n-1}, y_{n-1}\right), g x_{n}\right) \\
& +a_{5} p\left(F\left(x_{n}, y_{n}\right), g x_{n-1}\right)+a_{6} p\left(F\left(x_{n}, y_{n}\right), g x_{n}\right)+\epsilon^{n} \\
\leq & a_{1} p\left(g x_{n-1}, g x_{n}\right)+a_{2} p\left(g y_{n-1}, g y_{n}\right)+a_{3} p\left(g x_{n}, g x_{n-1}\right) \\
& +a_{4} p\left(g x_{n}, g x_{n}\right)+a_{5} p\left(g x_{n+1}, g x_{n-1}\right)+a_{6} p\left(g x_{n+1}, g x_{n}\right)+\epsilon^{n} \\
\leq & a_{1} p\left(g x_{n-1}, g x_{n}\right)+a_{2} p\left(g y_{n-1}, g y_{n}\right)+a_{3} p\left(g x_{n}, g x_{n-1}\right) \\
& +a_{4} p\left(g x_{n}, g x_{n}\right)+a_{5} p\left(g x_{n+1}, g x_{n}\right)+a_{5} p\left(g x_{n}, g x_{n-1}\right) \\
& -a_{5} p\left(g x_{n}, g x_{n}\right)+a_{6} p\left(g x_{n+1}, g x_{n}\right)+\epsilon^{n},
\end{aligned}
$$

that is,

$$
\begin{aligned}
\left(1-a_{5}-a_{6}\right) p\left(g x_{n}, g x_{n+1}\right) \leq & \left(a_{1}+a_{3}+a_{5}\right) p\left(g x_{n}, g x_{n-1}\right)+a_{2} p\left(g y_{n-1}, g y_{n}\right) \\
& +\left(a_{4}-a_{5}\right) p\left(g x_{n}, g x_{n}\right)+\epsilon^{n} .
\end{aligned}
$$


Interchanging the roles of $x_{n}$ and $x_{n+1}$ and using the symmetries of $p$ and $H_{p}$, we obtain

$$
\begin{aligned}
\left(1-a_{4}-a_{3}\right) p\left(g x_{n}, g x_{n+1}\right) \leq & \left(a_{1}+a_{6}+a_{4}\right) p\left(g x_{n}, g x_{n-1}\right)+a_{2} p\left(g y_{n-1}, g y_{n}\right) \\
& +\left(a_{5}-a_{4}\right) p\left(g x_{n}, g x_{n}\right)+\epsilon^{n} .
\end{aligned}
$$

It follows from (2) and (3) that

$$
\begin{aligned}
\left(2-a_{3}-a_{4}-a_{5}-a_{6}\right) p\left(g x_{n}, g x_{n+1}\right) \leq & \left(2 a_{1}+a_{3}+a_{4}+a_{5}+a_{6}\right) p\left(g x_{n}, g x_{n-1}\right) \\
& +2 a_{2} p\left(g y_{n-1}, g y_{n}\right)+2 \epsilon^{n} .
\end{aligned}
$$

Similarly, it can be obtained that

$$
\begin{aligned}
\left(2-a_{3}-a_{4}-a_{5}-a_{6}\right) p\left(g y_{n}, g y_{n+1}\right) \leq & \left(2 a_{1}+a_{3}+a_{4}+a_{5}+a_{6}\right) p\left(g y_{n}, g y_{n-1}\right) \\
+ & +2 a_{2} p\left(g x_{n-1}, g x_{n}\right)+2 \epsilon^{n} .
\end{aligned}
$$

For simplicity, set $p_{n}=p\left(g x_{n}, g x_{n+1}\right)+p\left(g y_{n}, g y_{n+1}\right)$, then it follows from (4) and (5) that

$$
\left(2-a_{3}-a_{4}-a_{5}-a_{6}\right) p_{n} \leq\left(2 a_{1}+2 a_{2}+a_{3}+a_{4}+a_{5}+a_{6}\right) p_{n-1}+4 \epsilon^{n}
$$

that is,

$$
p_{n} \leq \frac{2 a_{1}+2 a_{2}+a_{3}+a_{4}+a_{5}+a_{6}}{2-a_{3}-a_{4}-a_{5}-a_{6}} p_{n-1}+\frac{4 \epsilon^{n}}{2-a_{3}-a_{4}-a_{5}-a_{6}} \text {. }
$$

As $\epsilon>0$ was arbitrary, choose $\epsilon=\frac{2 a_{1}+2 a_{2}+a_{3}+a_{4}+a_{5}+a_{6}}{2-a_{3}-a_{4}-a_{5}-a_{6}}$; also, as $\sum_{i=1}^{6} a_{i}<1$, we have $\epsilon<1$. Therefore, from (6) we have

$$
p_{n} \leq \epsilon p_{n-1}+\frac{4 \epsilon^{n}}{1+a_{1}+a_{2}}
$$

From a successive application of the above inequality, we obtain

$$
\begin{aligned}
& p_{n} \leq \epsilon p_{n-1}+\frac{4 \epsilon^{n}}{1+a_{1}+a_{2}}, \\
& p_{n} \leq \epsilon\left[\epsilon p_{n-2}+\frac{4 \epsilon^{n-1}}{1+a_{1}+a_{2}}\right]+\frac{4 \epsilon^{n}}{1+a_{1}+a_{2}}, \\
& p_{n} \leq \epsilon^{2} p_{n-2}+\frac{8 \epsilon^{n}}{1+a_{1}+a_{2}}, \\
& \vdots \\
& p_{n} \leq \epsilon^{n} p_{0}+\frac{4 n \epsilon^{n}}{1+a_{1}+a_{2}} .
\end{aligned}
$$

For $m, n \in \mathbb{N}$ with $m>n$, using (7) we obtain

$$
\begin{aligned}
p\left(g x_{n}, g x_{m}\right)+p\left(g y_{n}, g y_{m}\right) \leq & p\left(g x_{n}, g x_{n+1}\right)+p\left(g y_{n}, g y_{n+1}\right)+p\left(g x_{n+1}, g x_{n+2}\right) \\
& +p\left(g y_{n+1}, g y_{n+2}\right)+\cdots+p\left(g x_{m-1}, g x_{m}\right)+p\left(g y_{m-1}, g y_{m}\right)
\end{aligned}
$$




$$
\begin{aligned}
= & p_{n}+p_{n+1}+\cdots+p_{m-1} \\
\leq & \epsilon^{n} p_{0}+\frac{4 n \epsilon^{n}}{1+a_{1}+a_{2}}+\epsilon^{n+1} p_{0}+\frac{4(n+1) \epsilon^{n+1}}{1+a_{1}+a_{2}} \\
& +\cdots+\epsilon^{m-1} p_{0}+\frac{4(m-1) \epsilon^{m-1}}{1+a_{1}+a_{2}} \\
= & p_{0} \sum_{i=0}^{m-n-1} \epsilon^{n+i}+\frac{4}{1+a_{1}+a_{2}} \sum_{i=0}^{m-n-1}(n+i) \epsilon^{n+i} .
\end{aligned}
$$

As $\epsilon<1$, it follows from the above inequality that

$$
\lim _{n, m \rightarrow \infty} p\left(g x_{n}, g x_{m}\right)=\lim _{n, m \rightarrow \infty} p\left(g y_{n}, g y_{m}\right)=0 .
$$

So, $\left\{g x_{n}\right\}$ and $\left\{g y_{n}\right\}$ are 0 -Cauchy sequences in $g(X)$; therefore, by the closedness of $g(X)$, there exists $w, z \in X$ such that

$$
\begin{aligned}
& \lim _{n \rightarrow \infty} p\left(g x_{n}, g w\right)=\lim _{n, m \rightarrow \infty} p\left(g x_{n}, g x_{m}\right)=p(g w, g w)=0, \\
& \lim _{n \rightarrow \infty} p\left(g y_{n}, g z\right)=\lim _{n, m \rightarrow \infty} p\left(g y_{n}, g y_{m}\right)=p(g z, g z)=0 .
\end{aligned}
$$

Using (1) we obtain

$$
\begin{aligned}
p(F(w, z), g w) \leq & p\left(F(w, z), g x_{n+1}\right)+p\left(g x_{n+1}, g w\right) \\
\leq & H_{p}\left(F(w, z), F\left(x_{n}, y_{n}\right)\right)+p\left(g x_{n+1}, g w\right) \\
\leq & a_{1} p\left(g w, g x_{n}\right)+a_{2} p\left(g z, g y_{n}\right)+a_{3} p(F(w, z), g w) \\
& +a_{4} p\left(F(w, z), g x_{n}\right)+a_{5} p\left(F\left(x_{n}, y_{n}\right), g w\right) \\
& +a_{6} p\left(F\left(x_{n}, y_{n}\right), g x_{n}\right)+p\left(g x_{n+1}, g w\right),
\end{aligned}
$$

that is,

$$
\begin{aligned}
\left(1-a_{3}-a_{4}\right) p(F(w, z), g w) \leq & a_{1} p\left(g w, g x_{n}\right)+a_{2} p\left(g z, g y_{n}\right)+a_{4} p\left(g w, g x_{n}\right) \\
& +a_{5} p\left(g x_{n+1}, g w\right)+a_{6} p\left(g x_{n+1}, g x_{n}\right)+p\left(g x_{n+1}, g w\right) \\
= & \left(a_{1}+a_{4}\right) p\left(g w, g x_{n}\right)+a_{2} p\left(g z, g y_{n}\right) \\
& +\left(1+a_{5}\right) p\left(g x_{n+1}, g w\right)+a_{6} p\left(g x_{n+1}, g x_{n}\right) .
\end{aligned}
$$

Using (8) and (9) and the fact that $1-a_{3}-a_{4}>0$ in the above inequality, we obtain

$$
p(F(w, z), g w)=p(g w, g w)=0 .
$$

Therefore, by Lemma $2, g w \in F(w, z)$. Similarly, $g z \in F(z, w)$. Thus $(w, z)$ is a coupled coincidence point and $(g w, g z)=\left(w_{c}, z_{c}\right)$ (say) is a point of coincidence of the mappings $F$ and $g$ with $p(g w, g w)=p(g z, g z)=p\left(w_{c}, w_{c}\right)=p\left(z_{c}, z_{c}\right)=0$.

The following is a coupled fixed point result for a set-valued mapping and it can be obtained by taking $g=I_{X}$ (that is an identity mapping of $X$ ) in the above theorem. 
Corollary 2 Let $(X, p)$ be a 0 -complete partial metric space, let $F: X \times X \rightarrow C B^{p}(X)$ be a mapping satisfying

$$
\begin{aligned}
H_{p}(F(x, y), F(u, v)) \leq & a_{1} p(x, u)+a_{2} p(y, v)+a_{3} p(F(x, y), x)+a_{4} p(F(x, y), u) \\
& +a_{5} p(F(u, v), x)+a_{6} p(F(u, v), u)
\end{aligned}
$$

for all $x, y, u, v \in X$, where $a_{i}$ are nonnegative reals such that $\sum_{i=1}^{6} a_{i}<1$. Then $F$ has $a$ coupled fixed point $(w, z) \in X \times X$ and $p(w, w)=p(z, z)=0$.

With suitable values of control constants in Theorem 3, one can obtain the following corollaries.

Corollary 3 Let $(X, p)$ be a 0 -complete partial metric space, let $F: X \times X \rightarrow C B^{p}(X)$ and $g: X \rightarrow X$ be mappings satisfying

$$
H_{p}(F(x, y), F(u, v)) \leq a_{1} p(g x, g u)+a_{2} p(g y, g v)
$$

for all $x, y, u, v \in X$, where $a_{1}$ and $a_{2}$ are nonnegative reals such that $a_{1}+a_{2}<1$. If $F(X \times X) \subseteq$ $g(X)$ and $g(X)$ is a closed subset of $X$, then $F$ and $g$ have a coupled point of coincidence $\left(w_{c}, z_{c}\right) \in X \times X$ and $p\left(w_{c}, w_{c}\right)=p\left(z_{c}, z_{c}\right)=0$.

Corollary 4 Let $(X, p)$ be a 0 -complete partial metric space, let $F: X \times X \rightarrow C B^{p}(X)$ and $g: X \rightarrow X$ be mappings satisfying

$$
\begin{aligned}
H_{p}(F(x, y), F(u, v)) \leq & a_{1} p(F(x, y), g x)+a_{2} p(F(x, y), g u)+a_{3} p(F(u, v), g x) \\
& +a_{4} p(F(u, v), g u)
\end{aligned}
$$

for all $x, y, u, v \in X$, where $a_{i}$ are nonnegative reals such that $\sum_{i=1}^{4} a_{i}<1$. If $F(X \times X) \subseteq g(X)$ and $g(X)$ is a closed subset of $X$, then $F$ and $g$ have a coupled point of coincidence $\left(w_{c}, z_{c}\right) \in$ $X \times X$ and $p\left(w_{c}, w_{c}\right)=p\left(z_{c}, z_{c}\right)=0$.

The following example illustrates the case when the results in partial metric spaces are applicable while the same results in usual metric spaces are not.

Example 2 Let $X=[0,1] \cap \mathbb{Q}$, and let $p: X \times X \rightarrow \mathbb{R}^{+}$be defined by

$$
p(x, y)=|x-y|+\max \{x, y\} \quad \text { for all } x, y \in X .
$$

Then the metric induced by $p$ is given by $d(x, y)=3|x-y|$ for all $x, y \in X$ and $(X, d)$ is not complete, therefore $(X, p)$ is not complete. Now, it is easy to see that $(X, p)$ is a 0 -complete partial metric space and every singleton subset of $X$ is closed with respect to $p$. Define $F: X \times X \rightarrow C B^{p}(X)$ and $g: X \rightarrow X$ by

$$
F(x, y)=\left\{\begin{array}{ll}
\{0\} & \text { if } x=y=1 ; \\
\left\{0, \frac{x+y}{8}\right\} & \text { otherwise }
\end{array} \text { and } g x=x \quad \text { for all } x \in X\right.
$$


We shall show that $F$ and $g$ satisfy all the conditions of Corollary 3 , with $a_{1}=a_{2}=\alpha \in$ $\left[\frac{1}{4}, \frac{1}{2}\right)$, while the metric versions of Corollary 3 are not applicable. We consider the following cases.

Case (i) If $x, y, u, v \in X \backslash\{1\}$ and $x+y \neq u+v$, then suppose $u+v<x+y$, so

$$
\begin{aligned}
H_{p} & (F(x, y), F(u, v)) \\
= & H_{p}\left(\left\{0, \frac{x+y}{8}\right\},\left\{0, \frac{u+v}{8}\right\}\right) \\
= & \max \left\{\sup _{a \in\left\{0, \frac{x+y}{8}\right\}} p\left(a,\left\{0, \frac{u+v}{8}\right\}\right), \sup _{a \in\left\{0, \frac{u+v}{8}\right\}} p\left(a,\left\{0, \frac{x+y}{8}\right\}\right)\right\} \\
= & \max \left\{p\left(\frac{x+y}{8},\left\{0, \frac{u+v}{8}\right\}\right), p\left(\frac{u+v}{8},\left\{0, \frac{x+y}{8}\right\}\right)\right\} \\
= & \max \left\{\min \left\{\frac{x+y}{4}, \frac{1}{8}|x-u+y-v|+\frac{1}{8} \max \{x+y, u+v\}\right\},\right. \\
& \left.\min \left\{\frac{u+v}{4}, \frac{1}{8}|x-u+y-v|+\frac{1}{8} \max \{x+y, u+v\}\right\}\right\} \\
= & \max \left\{\frac{1}{8}|x-u+y-v|+\frac{x+y}{8}, \min \left\{\frac{u+v}{4}, \frac{1}{8}|x-u+y-v|+\frac{x+y}{8}\right\}\right\} \\
= & \frac{1}{8}|x-u+y-v|+\frac{x+y}{8} \leq \frac{1}{8}[|x-u|+|y-v|]+\frac{x+y}{8} \\
\leq & \alpha[p(g x, g u)+p(g y, g v)],
\end{aligned}
$$

where $\frac{1}{8} \leq \alpha$. Similarly, we obtain the same result for $u+v>x+y$.

Case (ii) If $x, y, u, v \in X \backslash\{1\}$ and $x+y=u+v$, then

$$
\begin{aligned}
H_{p}(F(x, y), F(u, v)) & =H_{p}\left(\left\{0, \frac{x+y}{8}\right\},\left\{0, \frac{x+y}{8}\right\}\right) \\
& =\sup _{a \in\left\{0, \frac{x+y}{8}\right\}} p(a, a) \\
& =\frac{x+y}{8} \leq \frac{\max \{x, u\}+\max \{y, v\}}{8} \\
& \leq \alpha[p(g x, g u)+p(g y, g v)],
\end{aligned}
$$

where $\frac{1}{8} \leq \alpha$. Similarly, if any one of $x, y, u, v$ is equal to 1 , then we obtain the same result.

Case (iii) If any one of $(x, y),(u, v)$ is equal to $(1,1)$, for example, let $(u, v)=(1,1)$ and $(x, y) \neq(1,1)$, then we have

$$
\begin{aligned}
H_{p}(F(x, y), F(u, v)) & =H_{p}\left(\left\{0, \frac{x+y}{8}\right\},\{0\}\right) \\
& =\max \left\{\sup _{a \in\left\{0, \frac{x+y}{8}\right\}} p(a,\{0\}), \sup _{a \in\{0\}} p\left(a,\left\{0, \frac{x+y}{8}\right\}\right)\right\} \\
& =\max \left\{\frac{x+y}{4}, 0\right\}=\frac{x+y}{4} \\
& \leq \alpha[p(g x, g u)+p(g y, g v)],
\end{aligned}
$$


where $\frac{1}{4} \leq \alpha$. Similarly, the condition (10) is satisfied for $a_{1}=a_{2}=\alpha \in\left[\frac{1}{4}, \frac{1}{2}\right)$ in all possible cases and $0=g 0 \in F(0,0)$, that is, $(0,0)$ is a coupled coincidence point of $F$ and $g$ (here it is the unique common fixed point of $F$ and $g$ ).

Note that, the metric spaces $(X, \rho)$ and $(X, d)$ (where $\rho$ is usual and $d$ is metric induced by $p$ ) are not complete, therefore metric versions of Corollary 3 are not applicable. Also, this example shows that $F$ and $g$ do not satisfy the metric versions of inequality (10). Indeed, if $H_{\rho}$ is the Hausdorff metric induced by the usual metric $\rho$, then for $x=y=u=1, v=\frac{9}{10}$, we have

$$
H_{\rho}(F(x, y), F(u, v))=H_{\rho}\left(\{0\},\left\{0, \frac{19}{80}\right\}\right)=\frac{19}{80}
$$

and

$$
a_{1} \rho(g x, g u)+a_{2} \rho(g y, g v)=\frac{1}{10} a_{2} .
$$

Therefore, we cannot find the nonnegative reals $a_{1}, a_{2}$ such that

$$
H_{\rho}(F(x, y), F(u, v)) \leq a_{1} \rho(g x, g u)+a_{2} \rho(g y, g v)
$$

for all $x, y, u, v \in X$ with $a_{1}+a_{2}<1$. So, $F$ is not a contraction (in view of contraction condition (10)) with respect to the usual metric $\rho$. Similarly, one can see that $F$ is not a contraction with respect to the induced metric $d$.

The following theorem provides a sufficient condition for the uniqueness of a coupled point of coincidence and a common fixed point of the hybrid pair $\{F, g\}$.

Theorem 4 Let $(X, p)$ be a 0-complete partial metric space, let $F: X \times X \rightarrow C B^{p}(X)$ and $g: X \rightarrow X$ be mappings such that all the conditions of Theorem 3 are satisfied and, for any coupled coincidence point $(w, z)$ of $F$ and $g$, we have $F(w, z)=\{g w\}$ and $F(z, w)=\{g z\}$, then $F$ and $g$ have a unique coupled point of coincidence. Suppose in addition that the hybrid pair $\{F, g\}$ is weakly compatible, then $F$ and $g$ have a unique coupled common fixed point.

Proof The existence of a coupled coincidence point $(w, z)$ and a point of coincidence $\left(w_{c}, z_{c}\right)$ follows from Theorem 3. Suppose that, for any coupled coincidence point $(w, z)$ of $F$ and $g$, we have $F(w, z)=\{g w\}=\left\{w_{c}\right\}$ and $F(z, w)=\{g z\}=\left\{z_{c}\right\}$. We shall show that the coupled point of coincidence is unique. Let $\left(w^{\prime}, z^{\prime}\right)$ be another coupled coincidence point and $\left(w_{c}^{\prime}, z_{c}^{\prime}\right)$ be the coupled point of coincidence of $F$ and $g$, that is, $w_{c}^{\prime}=g w^{\prime} \in F\left(w^{\prime}, z^{\prime}\right)$, $z_{c}^{\prime}=g z^{\prime} \in F\left(z^{\prime}, w^{\prime}\right)$ and $F\left(w^{\prime}, z^{\prime}\right)=\left\{g w^{\prime}\right\}=\left\{w_{c}^{\prime}\right\}, F\left(z^{\prime}, w^{\prime}\right)=\left\{g z^{\prime}\right\}=\left\{z_{c}^{\prime}\right\}$.

Using (1), we obtain

$$
\begin{aligned}
p\left(g w, g w^{\prime}\right)= & H_{p}\left(\{g w\},\left\{g w^{\prime}\right\}\right) \\
= & H_{p}\left(F(w, z), F\left(w^{\prime}, z^{\prime}\right)\right) \\
\leq & a_{1} p\left(g w, g w^{\prime}\right)+a_{2} p\left(g z, g z^{\prime}\right)+a_{3} p(F(w, z), g w)+a_{4} p\left(F(w, z), g w^{\prime}\right) \\
& +a_{5} p\left(F\left(w^{\prime}, z^{\prime}\right), g w\right)+a_{6} p\left(F\left(w^{\prime}, z^{\prime}\right), g w^{\prime}\right)
\end{aligned}
$$




$$
\begin{aligned}
= & a_{1} p\left(g w, g w^{\prime}\right)+a_{2} p\left(g z, g z^{\prime}\right)+a_{3} p(g w, g w)+a_{4} p\left(g w, g w^{\prime}\right) \\
& +a_{5} p\left(g w^{\prime}, g w\right)+a_{6} p\left(g w^{\prime}, g w^{\prime}\right) .
\end{aligned}
$$

Again, using (1) we obtain

$$
\begin{aligned}
p\left(g z, g z^{\prime}\right)= & H_{p}\left(\{g z\},\left\{g z^{\prime}\right\}\right) \\
= & H_{p}\left(F(z, w), F\left(z^{\prime}, w^{\prime}\right)\right) \\
\leq & a_{1} p\left(g z, g z^{\prime}\right)+a_{2} p\left(g w, g w^{\prime}\right)+a_{3} p(F(z, w), g z)+a_{4} p\left(F(z, w), g z^{\prime}\right) \\
& +a_{5} p\left(F\left(z^{\prime}, w^{\prime}\right), g z\right)+a_{6} p\left(F\left(z^{\prime}, w^{\prime}\right), g z^{\prime}\right) \\
= & a_{1} p\left(g z, g z^{\prime}\right)+a_{2} p\left(g w, g w^{\prime}\right)+a_{3} p(g z, g z)+a_{4} p\left(g z, g z^{\prime}\right) \\
& +a_{5} p\left(g z^{\prime}, g z\right)+a_{6} p\left(g z^{\prime}, g z^{\prime}\right) .
\end{aligned}
$$

It follows from (11) and (12) that

$$
\begin{aligned}
p\left(g w, g w^{\prime}\right)+p\left(g z, g z^{\prime}\right) \leq & \left(a_{1}+a_{2}+a_{4}+a_{5}\right) p\left(g w, g w^{\prime}\right)+a_{3} p(g w, g w) \\
& +a_{6} p\left(g w^{\prime}, g w^{\prime}\right)+\left(a_{1}+a_{2}+a_{4}+a_{5}\right) p\left(g z, g z^{\prime}\right) \\
& +a_{3} p(g z, g z)+a_{6} p\left(g z^{\prime}, g z^{\prime}\right) \\
= & \left(a_{1}+a_{2}+a_{3}+a_{4}+a_{5}+a_{6}\right)\left[p\left(g w, g w^{\prime}\right)+p\left(g z, g z^{\prime}\right)\right] .
\end{aligned}
$$

As $\sum_{i=1}^{6} a_{i}<1$, it follows from the above inequality that $p\left(g w, g w^{\prime}\right)+p\left(g z, g z^{\prime}\right)=0$, that is, $p\left(g w, g w^{\prime}\right)=p\left(g z, g z^{\prime}\right)=0$, so $w_{c}=g w=g w^{\prime}=w_{c}^{\prime}$ and $z_{c}=g z=g z^{\prime}=z_{c}^{\prime}$. Therefore, a coupled point of coincidence, that is, $\left(w_{c}, z_{c}\right)$, of $F$ and $g$ is unique.

Suppose that $F$ and $g$ are weakly compatible, then we have

$$
\begin{aligned}
& g\left\{w_{c}\right\}=g F(w, z) \subseteq F(g w, g z) \quad \text { that is } \quad\left\{g w_{c}\right\} \subseteq F\left(w_{c}, z_{c}\right) \quad \text { and } \\
& g\left\{z_{c}\right\}=g F(z, w) \subseteq F(g z, g w) \quad \text { that is } \quad\left\{g z_{c}\right\} \subseteq F\left(z_{c}, w_{c}\right) .
\end{aligned}
$$

Therefore, $\left(g w_{c}, g z_{c}\right)$ is another coupled point of coincidence of $F$ and $g$, and by uniqueness we have $w_{c}=g w_{c} \in F\left(w_{c}, z_{c}\right)$ and $z_{c}=g z_{c} \in F\left(z_{c}, w_{c}\right)$. Thus $\left(z_{c}, w_{c}\right)$ is the unique coupled common fixed point of $F$ and $g$.

The following theorem is a new result for a hybrid pair of mappings in partial metric as well as in metric spaces.

Theorem 5 Let $(X, p)$ be a 0 -complete partial metric space, let $F: X \times X \rightarrow C B^{p}(X)$ and $g: X \rightarrow X$ be mappings satisfying

$$
\begin{aligned}
H_{p}(F(x, y), F(u, v)) \leq & a_{1} p(F(y, x), g y)+a_{2} p(F(y, x), g v)+a_{3} p(F(v, u), g y) \\
& +a_{4} p(F(v, u), g v)
\end{aligned}
$$

for all $x, y, u, v \in X$, where $a_{i}$ are nonnegative reals such that $\sum_{i=1}^{4} a_{i}<1$. If $F(X \times X) \subseteq g(X)$ and $g(X)$ is a closed subset of $X$, then $F$ and $g$ have a coupled point of coincidence $\left(w_{c}, z_{c}\right) \in$ $X \times X$ and $p\left(g w_{c}, g w_{c}\right)=p\left(g z_{c}, g z_{c}\right)=0$. 
Proof By a similar process as used in Theorem 3, we can find two sequences $\left\{x_{n}\right\}$ and $\left\{y_{n}\right\}$ such that

$$
\begin{aligned}
& g x_{n+1} \in F\left(x_{n}, y_{n}\right) \quad \text { and } g y_{n+1} \in F\left(y_{n}, x_{n}\right), \\
& p\left(g x_{n}, g x_{n+1}\right) \leq H_{p}\left(F\left(x_{n-1}, y_{n-1}\right), F\left(x_{n}, y_{n}\right)\right)+\epsilon^{n}, \\
& p\left(g y_{n}, g y_{n+1}\right) \leq H_{p}\left(F\left(y_{n-1}, x_{n-1}\right), F\left(y_{n}, x_{n}\right)\right)+\epsilon^{n},
\end{aligned}
$$

where $\epsilon>0$ is arbitrary.

From the above inequality and (13), we obtain

$$
\begin{aligned}
p\left(g x_{n}, g x_{n+1}\right) \leq & H_{p}\left(F\left(x_{n-1}, y_{n-1}\right), F\left(x_{n}, y_{n}\right)\right)+\epsilon^{n} \\
\leq & a_{1} p\left(F\left(y_{n-1}, x_{n-1}\right), g y_{n-1}\right)+a_{2} p\left(F\left(y_{n-1}, x_{n-1}\right), g y_{n}\right) \\
& +a_{3} p\left(F\left(y_{n}, x_{n}\right), g y_{n-1}\right)+a_{4} p\left(F\left(y_{n}, x_{n}\right), g y_{n}\right)+\epsilon^{n} \\
\leq & a_{1} p\left(g y_{n}, g y_{n-1}\right)+a_{2} p\left(g y_{n}, g y_{n}\right)+a_{3} p\left(g y_{n+1}, g y_{n-1}\right) \\
& +a_{4} p\left(g y_{n+1}, g y_{n}\right)+\epsilon^{n}
\end{aligned}
$$

that is,

$$
\begin{aligned}
p\left(g x_{n}, g x_{n+1}\right) \leq & \left(a_{1}+a_{3}\right) p\left(g y_{n}, g y_{n-1}\right)+\left(a_{3}+a_{4}\right) p\left(g y_{n+1}, g y_{n}\right)+\epsilon^{n} \\
& +\left(a_{2}-a_{3}\right) a_{2} p\left(g y_{n}, g y_{n}\right) .
\end{aligned}
$$

Interchanging the roles of $x_{n}$ and $x_{n+1}$ and using the symmetries of $p$ and $H_{p}$, we obtain

$$
\begin{aligned}
p\left(g x_{n}, g x_{n+1}\right) \leq & \left(a_{4}+a_{2}\right) p\left(g y_{n}, g y_{n-1}\right)+\left(a_{2}+a_{1}\right) p\left(g y_{n+1}, g y_{n}\right) \\
& +\left(a_{3}-a_{2}\right) a_{2} p\left(g y_{n}, g y_{n}\right)+\epsilon^{n} .
\end{aligned}
$$

It follows from (14) and (15) that

$$
\begin{aligned}
2 p\left(g x_{n}, g x_{n+1}\right) \leq & \left(a_{1}+a_{2}+a_{3}+a_{4}\right)\left[p\left(g y_{n}, g y_{n-1}\right)\right. \\
& \left.+p\left(g y_{n+1}, g y_{n}\right)\right]+2 \epsilon^{n} .
\end{aligned}
$$

Similarly, it can be shown that

$$
\begin{aligned}
2 p\left(g y_{n}, g y_{n+1}\right) \leq & \left(a_{1}+a_{2}+a_{3}+a_{4}\right)\left[p\left(g x_{n}, g x_{n-1}\right)\right. \\
& \left.+p\left(g x_{n+1}, g x_{n}\right)\right]+2 \epsilon^{n} .
\end{aligned}
$$

For simplicity, set $p_{n}=p\left(g x_{n}, g x_{n+1}\right)+p\left(g y_{n}, g y_{n+1}\right)$, then it follows from (16) and (17) that

$$
p_{n} \leq \frac{a_{1}+a_{2}+a_{3}+a_{4}}{2-a_{1}-a_{2}-a_{3}-a_{4}} p_{n-1}+\frac{4 \epsilon^{n}}{2-a_{1}-a_{2}-a_{3}-a_{4}} .
$$

As $\epsilon>0$ was arbitrary, choose $\epsilon=\frac{a_{1}+a_{2}+a_{3}+a_{4}}{2-a_{1}-a_{2}-a_{3}-a_{4}}$; also, as $\sum_{i=1}^{4} a_{i}<1$, we have $\epsilon<1$. Therefore

$$
p_{n} \leq \epsilon p_{n-1}+\frac{4 \epsilon^{n}}{2-a_{1}-a_{2}-a_{3}-a_{4}} \leq \epsilon p_{n-1}+4 \epsilon^{n} .
$$


It follows from a successive application of the above inequality that

$$
\begin{aligned}
& p_{n} \leq \epsilon p_{n-1}+4 \epsilon^{n}, \\
& p_{n} \leq \epsilon\left[\epsilon p_{n-2}+4 \epsilon^{n-1}\right]+4 \epsilon^{n}, \\
& p_{n} \leq \epsilon^{2} p_{n-2}+8 \epsilon^{n} \\
& \vdots \\
& p_{n} \leq \epsilon^{n} p_{0}+4 n \epsilon^{n} .
\end{aligned}
$$

For $m, n \in \mathbb{N}$ with $m>n$, using (18) we obtain

$$
\begin{aligned}
p\left(g x_{n}, g x_{m}\right)+p\left(g y_{n}, g y_{m}\right) \leq & p\left(g x_{n}, g x_{n+1}\right)+p\left(g y_{n}, g y_{n+1}\right)+p\left(g x_{n+1}, g x_{n+2}\right) \\
& +p\left(g y_{n+1}, g y_{n+2}\right)+\cdots+p\left(g x_{m-1}, g x_{m}\right) \\
& +p\left(g y_{m-1}, g y_{m}\right) \\
= & p_{n}+p_{n+1}+\cdots+p_{m-1} \\
\leq & \epsilon^{n} p_{0}+4 n \epsilon^{n}+\epsilon^{n+1} p_{0}+4(n+1) \epsilon^{n+1}+\cdots+\epsilon^{m-1} p_{0} \\
& +4(m-1) \epsilon^{m-1} \\
= & p_{0} \sum_{i=0}^{m-n-1} \epsilon^{n+i}+4 \sum_{i=0}^{m-n-1}(n+i) \epsilon^{n+i} .
\end{aligned}
$$

As $\epsilon<1$, it follows from the above inequality that

$$
\lim _{n, m \rightarrow \infty} p\left(g x_{n}, g x_{m}\right)=\lim _{n, m \rightarrow \infty} p\left(g y_{n}, g y_{m}\right)=0 .
$$

So, $\left\{g x_{n}\right\}$ and $\left\{g y_{n}\right\}$ are 0 -Cauchy sequences in $g(X)$, therefore by the closedness of $g(X)$, there exists $w, z \in X$ such that

$$
\begin{aligned}
& \lim _{n \rightarrow \infty} p\left(g x_{n}, g w\right)=\lim _{n, m \rightarrow \infty} p\left(g x_{n}, g x_{m}\right)=p(g w, g w)=0, \\
& \lim _{n \rightarrow \infty} p\left(g y_{n}, g z\right)=\lim _{n, m \rightarrow \infty} p\left(g y_{n}, g y_{m}\right)=p(g z, g z)=0 .
\end{aligned}
$$

We shall show that $p(F(w, z), g w)=p(g w, g w)=0$ and $p(F(z, w), g z)=p(g z, g z)=0$.

For all $n \in \mathbb{N}$, we have

$$
\begin{aligned}
p(F(w, z), g w) \leq & p\left(F(w, z), g x_{n+1}\right)+p\left(g x_{n+1}, g w\right) \\
\leq & H_{p}\left(F(w, z), F\left(x_{n}, y_{n}\right)\right)+p\left(g x_{n+1}, g w\right) \\
\leq & a_{1} p(F(z, w), g z)+a_{2} p\left(F(z, w), g y_{n}\right)+a_{3} p\left(F\left(y_{n}, x_{n}\right), g z\right) \\
& +a_{4} p\left(F\left(y_{n}, x_{n}\right), g y_{n}\right)+p\left(g x_{n+1}, g w\right) \\
\leq & \left(a_{1}+a_{2}\right) p(F(z, w), g z)+a_{2} p\left(g z, g y_{n}\right)+a_{3} p\left(g y_{n+1}, g z\right) \\
& +a_{4} p\left(g y_{n+1}, g y_{n}\right)+p\left(g x_{n+1}, g w\right) .
\end{aligned}
$$


Using (19) and (20) in the above inequality, we obtain

$$
p(F(w, z), g w) \leq\left(a_{1}+a_{2}\right) p(F(z, w), g z)<p(F(z, w), g z) .
$$

Again, for all $n \in \mathbb{N}$, we have

$$
\begin{aligned}
p(F(z, w), g z) \leq & p\left(F(z, w), g y_{n+1}\right)+p\left(g y_{n+1}, g z\right) \\
\leq & H_{p}\left(F(z, w), F\left(y_{n}, x_{n}\right)\right)+p\left(g y_{n+1}, g z\right) \\
\leq & a_{1} p(F(w, z), g w)+a_{2} p\left(F(w, z), g x_{n}\right)+a_{3} p\left(F\left(x_{n}, y_{n}\right), g w\right) \\
& +a_{4} p\left(F\left(x_{n}, y_{n}\right), g x_{n}\right)+p\left(g y_{n+1}, g z\right) \\
\leq & \left(a_{1}+a_{2}\right) p(F(w, z), g w)+a_{2} p\left(g w, g x_{n}\right)+a_{3} p\left(g x_{n+1}, g w\right) \\
& +a_{4} p\left(g x_{n+1}, g x_{n}\right)+p\left(g y_{n+1}, g z\right) .
\end{aligned}
$$

Using (20) and (19) in the above inequality, we obtain

$$
p(F(z, w), g z) \leq\left(a_{1}+a_{2}\right) p(F(w, z), g w)<p(F(w, z), g w) .
$$

Note that if $p(F(w, z), g w) \neq p(g w, g w)=0$ or $p(F(z, w), g z) \neq p(g z, g z)=0$, then (21) and (22) give a contradiction. Therefore, we have $p(F(w, z), g w)=p(g w, g w)=0$ and $p(F(z, w), g z)=$ $p(g z, g z)=0$, and by Lemma $2, g w \in F(w, z)$ and $g z \in F(z, w)$. Thus $(w, z)$ is a coupled coincidence point and $(g w, g z)=\left(w_{c}, z_{c}\right)$ (say) is a point of coincidence of the mappings $F$ and $g$ with $p(g w, g w)=p(g z, g z)=p\left(w_{c}, w_{c}\right)=p\left(z_{c}, z_{c}\right)=0$.

The following is a coupled fixed point result for a set-valued mapping and can be obtained by taking $g=I_{X}$ (that is an identity mapping of $X$ ) in the above theorem.

Corollary 5 Let $(X, p)$ be a 0 -complete partial metric space, let $F: X \rightarrow C B^{p}(X)$ be a mapping satisfying

$$
\begin{aligned}
H_{p}(F(x, y), F(u, v)) \leq & a_{1} p(F(y, x), y)+a_{2} p(F(y, x), v)+a_{3} p(F(v, u), y) \\
& +a_{4} p(F(v, u), v)
\end{aligned}
$$

for all $x, y, u, v \in X$, where $a_{i}$ are nonnegative reals such that $\sum_{i=1}^{4} a_{i}<1$. Then $F$ has $a$ coupled fixed point $(w, z) \in X \times X$ and $p(w, w)=p(z, z)=0$.

Theorem 6 Let $(X, p)$ be a 0-complete partial metric space, let $F: X \times X \rightarrow C B^{p}(X)$ and $g: X \rightarrow X$ be mappings such that all the conditions of Theorem 5 are satisfied, and for any coupled coincidence point $(w, z)$ of $F$ and $g$, we have $F(w, z)=\{g w\}$ and $F(z, w)=\{g z\}$. Then $F$ and $g$ have a unique coupled point of coincidence. Suppose in addition that the hybrid pair $\{F, g\}$ is weakly compatible, then $F$ and g have a unique coupled common fixed point.

Proof The proof of this theorem is followed by a similar process as used in Theorem 4 . 


\section{Competing interests}

The authors declare that they have no competing interests.

\section{Authors' contributions}

All authors contributed equally and significantly in writing this paper. All authors read and approved the final manuscript.

\section{Author details}

${ }^{1}$ College of Mathematics and Information Science, Jiangxi Normal University, Nanchang, Jiangxi 330022, People's Republic of China. ${ }^{2}$ Department of Applied Mathematics, Shri Vaishnav Institute of Technology and Science, Gram Baroli, Sanwer Road, Indore, MP 453331, India. ${ }^{3}$ Faculty of Mechanical Engineering, University of Belgrade, Kraljice Marije 16, Beograd, 11120, Serbia.

\section{Acknowledgements}

Wei Long acknowledges support from the NSF of China, and the Research Project of Jiangxi Normal University (2012-114).

\section{Received: 3 January 2013 Accepted: 15 May 2013 Published: 4 June 2013}

\section{References}

1. Nadler, SB Jr.: Multi-valued contraction mappings. Pac. J. Math. 30, 475-488 (1969)

2. Matthews, SG: Partial metric topology. In: Proc. 8th Summer Conference on General Topology and Applications. Ann. New York Acad. Sci., vol. 728, pp. 183-197 (1994)

3. Abdeljawad, T: Fixed points of generalized weakly contractive mappings in partial metric spaces. Math. Comput. Model. 54, 2923-2927 (2011)

4. Abdeljawad, T, Karapinar, E, Taş, K: Existence and uniqueness of a common fixed point on partial metric spaces. Appl. Math. Lett. 24, 1900-1904 (2011)

5. Ahmad, AGB, Fadail, ZM, Rajić, VC, Radenović, S: Nonlinear contractions in 0-complete partial metric spaces. Abstr. Appl. Anal. 2012, Article ID 451239 (2012). doi:10.1155/2012/451239

6. Altun, I, Acar, O: Fixed point theorems for weak contractions in the sense of Berinde on partial metric spaces. Topol. Appl. 159, 2642-2648 (2012)

7. Altun, I, Romaguera, S: Characterizations of partial metric completeness in terms of weakly contractive mappings having fixed point. Appl. Anal. Discrete Math. 6, 247-256 (2012)

8. Altun, I, Sola, F, Simsek, H: Generalized contractions on partial metric spaces. Topol. Appl. 157, 2778-2785 (2010)

9. Aydi, H, Abbas, M, Vetro, C: Partial Hausdorff metric and Nadler's fixed point theorem on partial metric spaces. Topol. Appl. 159(14), 3234-3242 (2012)

10. Di Bari, C, Kadelburg, Z, Nashine, HK, Radenović, S: Common fixed points of $g$-quasicontractions and related mappings in 0-complete partial metric spaces. Fixed Point Theory Appl. 2012, 113 (2012). doi:10.1186/1687-1812-2012-113

11. Bukatin, M, Kopperman, R, Matthews, S, Pajoohesh, H: Partial metric spaces. Am. Math. Mon. 116, 708-718 (2009)

12. Cirić, L, Samet, B, Aydi, H, Vetro, C: Common fixed points of generalized contractions on partial metric spaces and an application. Appl. Math. Comput. 218, 2398-2406 (2011)

13. Đukić, D, Kadelburg, Z, Radenović, S: Fixed points of Geraghty-type mappings in various generalized metric spaces. Abstr. Appl. Anal. 2011, Article ID 561245 (2011). doi:10.1155/2011/561245

14. Ilić, D, Pavlović, V, Rakočević, V: Extensions of Zamfirescu theorem to partial metric spaces. Math. Comput. Model. 55, 801-809 (2012)

15. Ilić, D, Pavlović, V, Rakoćević, V: Some new extensions of Banach's contraction principle to partial metric spaces. Appl. Math. Lett. 24, 1326-1330 (2011)

16. Kadelburg, Z, Nashine, HK, Radenović, S: Fixed point results under various contractive conditions in partial metric spaces. Rev. R. Acad. Cienc. Exactas Fís. Nat., Ser. A Mat. (2012). doi:10.1007/s13398-012-0066-6

17. Romaguera, S: A Kirk type characterization of completeness for partial metric spaces. Fixed Point Theory Appl. 2010 Article ID 493298 (2010)

18. Romaguera, S: Fixed point theorems for generalized contractions on partial metric spaces. Topol. Appl. 159, 194-199 (2012)

19. Romaguera, S: Matkowski's type theorems for generalized contractions on (ordered) partial metric spaces. Appl. Gen. Topol. 12(2), 213-220 (2011)

20. Romaguera, S: On Nadler's fixed point theorem for partial metric spaces. Math. Sci. Appl. E-Notes 1(1), 1-8 (2013)

21. Shobkolaei, N, Sedghi, S, Roshan, JR, Altun, I: Common fixed point of mappings satisfying almost generalized $(S, T)$-contractive condition in partially ordered partial metric spaces. Appl. Math. Comput. 219, 443-452 (2012)

22. Shukla, S, Radenović, S: Some common fixed point theorems for F-contraction type mappings in 0-complete partial metric spaces. J. Math. 2013, Article ID 878730 (2013). doi:10.1155/2013/878730

23. Bhashkar, TG, Lakshmikantham, V: Fixed point theorems in partially ordered metric spaces and applications. Nonlinear Anal. TMA 65(7), 1379-1393 (2006). doi:10.1016/j.na.2005.10.017

24. Abbas, M, Ćirić, L, Damjanović, B, Khan, MA: Coupled coincidence and common fixed point theorems for hybrid pair of mappings. Fixed Point Theory Appl. 2012, 4 (2012). doi:10.1186/1687-1812-2012-4

25. Aydi, H, Abbas, M, Postolache, M: Coupled coincidence points for hybrid pair of mappings via mixed monotone property. J. Adv. Math. Stud. 5(1), 118-126 (2012)

26. Rao, KPR, Kishore, GNV, Tas, K: A unique common tripled fixed point theorem for hybrid pair of maps. Abstr. Appl. Anal. 2012, Article ID 750403 (2012)

27. Al-Thagafi, MA, Shahzad, N: Coincidence points, generalized /-nonexpansive multimaps and applications. Nonlinear Anal. TMA 67(7), 2180-2188 (2007). doi:10.1016/j.na.2006.08.042

28. Hong, $\mathrm{SH}$ : Fixed points of discontinuous multivalued increasing operators in Banach spaces with applications. J. Math. Anal. Appl. 282, 151-162 (2003). doi:10.1016/S0022-247X(03)00111-2

29. Hong, SH: Fixed points for mixed monotone multivalued operators in Banach spaces with applications. J. Math. Anal. Appl. 337, 333-342 (2008). doi:10.1016/j.jmaa.2007.03.091 
30. Hong, SH, Guan, D, Wang, L: Hybrid fixed points of multivalued operators in metric spaces with applications. Nonlinear Anal. TMA 70, 4106-4117 (2009). doi:10.1016/j.na.2008.08.020

doi:10.1186/1687-1812-2013-145

Cite this article as: Long et al.: Some coupled coincidence and common fixed point results for a hybrid pair of mappings in 0-complete partial metric spaces. Fixed Point Theory and Applications 2013 2013:145.

Submit your manuscript to a SpringerOpen ${ }^{\circ}$ journal and benefit from:

- Convenient online submission

- Rigorous peer review

- Immediate publication on acceptance

Open access: articles freely available online

- High visibility within the field

- Retaining the copyright to your article

Submit your next manuscript at $>$ springeropen.com 